\author{
Alessandro Lanza \\ International Energy Agency, Paris, and University College, London \\ alessandro.lanza@iea.org \\ Francesco Pigliaru \\ University of Cagliari and CRENoS \\ pigliaru@unica.it

\section{WHY ARE TOURISM COUNTRIES SMALL AND FAST-GROWING?}

\begin{abstract}
International tourism is today one of the most important tradable sectors, with expenditure on tourist goods and services representing some $8 \%$ of total world export receipts and 5\% of world GDP. Cross-country data for 1985-95 on tourism specialisation and economic growth reveal the following regularities: (i) many tourism countries have grown faster compared to the other countries; and (ii) they are small. We use a two-sector endogenous growth model to obtain explanatory hypotheses about these two findings. In particular, we define the conditions required for small countries to specialise in tourism and to enter the faster growth path. Our suggestion is that what matters is a country's relative endowment of the natural resource, rather than its absolute size.
\end{abstract}

January 1999 


\section{Introduction*}

Having grown faster than the world GDP since the 1950s, international tourism is today one of the most important tradable sectors, with expenditure on tourist goods and services representing some $8 \%$ of total world export receipts and 5\% of world GDP.

In spite of this, the importance of this sector for a country's overall growth performance has been often neglected in the economic literature. For instance, in the recent impressive survey on the economic analysis of tourism [Sinclair (1998)], only very few papers out of the hundreds reviewed deal explicitly with the long-run growth consequences of specialisation in tourism. Consequently, not much work can be found on theoretical models aimed at explaining some interesting empirical findings characterising the relationship between economic growth and tourism specialisation in cross-country data.

Consider, for instance, the following experiment in which two separate lists of countries from the World Bank data set ${ }^{1}$ are used. The first list includes the top fifteen fastest growing countries in per capita income, from 1985 to 19952 . The second includes the fifteen countries with the highest degree of specialisation in tourism, defined as share of international tourism receipt with respect to the value added 3 . By simply comparing these two lists we find that seven out of the fifteen "tourism" countries do appear in the list of the fifteen fastest growing ones -- namely, St. Kitts and Nevis (per capita income average growth rate 1985-95: 5.9\%), Singapore (5.4\%), Antigua and Barbuda (5.3\%), Maldives (5.1\%), Mauritius (5.1\%), Seychelles (4.5\%) and Cyprus (4.5\%). While this evidence is far for being conclusive about the effects of tourism specialisation on growth, it is enough at least to

* This paper was written while one of the authors (F. Pigliaru) was visiting the D epartment of Economics at Soas, University of London.

1 World D evelopment Indicators 1998.

2 The first list includes the following countries: China (9.0\%), Korea, Rep. (7.7\%), Thailand $(7.6 \%)$, Suriname $(7.0 \%)$, St. Kitts and Nevis $(5.9 \%)$, Singapore $(5.4 \%)$, Antigua and Barbuda (5.3\%), Chile (5.3\%), Indonesia (5.3\%), Maldives (5.1\%), Mauritius (5.1\%), Malta (4.8\%), Hong Kong (4.6\%), Seychelles (4.5\%), Cyprus (4.5\%). In brackets the average annual increase of the per capita income from 1985 to 1995.

3 This second list includes Antigua and Barbuda (94.7\%), St. Kitts and Nevis (42.3\%), Barbados (41.1\%), Grenada (27.6\%), St. Vincent and the Grenadines (25.6\%), Cyprus (23.6\%), Jamaica (22.9\%), Seychelles (21.7\%), D ominica (17.9\%), Mauritius (11.8\%), Jordan (11.2\%), Singapore (10.8\%), Gambia (10.8\%), Dominican Republic (10.7\%), Guyana (10.4\%). In brackets the average specialisation degree over the period 1985 to 1995. 
show that tourism can make a country grow fast.

The above exercise unveils a second peculiarity. All fifteen countries with a high degree of specialisation in tourism share a rather evident feature: they are small countries ${ }^{4}$. This suggestive evidence points to the likely existence of two empirical regularities which might characterise the tourism sector when viewed from a macroeconomic perspective: (i) tourism specialisation can make a country grow fast; (ii) countries specialised in tourism are generally small ones. While more evidence is clearly required to validate the status of "empirical regularity" for these two findings, the evidence discussed so far is enough, in our opinion, to prompt a simple research agenda aimed at generating a joint explanation of points (i) and (ii).

The rest of the paper is divided into two parts. Section 2 considers the relation between tourism specialisation and economic growth. The main objective of this section is to show what are the conditions under which tourism specialisation is not detrimental to economic growth. To this aim, we use a simple endogenous growth theory framework based on Lucas (1988). Once this step is accomplished, we address the second question concerning the dimension issue. In Section 3 we discuss two alternative explanations of point (ii), and assess their consistency with respect to the hypothesis put forward to explain point (i).

\section{Tourism specialisation and economic growth}

Point (i) above indicates that tourism specialisation might not be detrimental to economic growth. While obviously no sector is "detrimental" to growth in an exogenous growth setting, things may be very different when the growth rate is endogenously determined. Much of the recent literature in this field points to the key positive role the more innovative sectors play in such determination. Considering countries in isolation, a larger innovative sector may spur faster growth in the long run. If trade induces different countries to specialise in sectors with different dynamic potentials, and technological spillovers across sectors and countries are not strong enough, then uneven growth is normally obtained [Grossman and Helpman (1991); more recently, Aghion and Howitt (1998)].

4 Using a sample of 200 independent states, Liu and Jenkins (1996) find that in $1990 \mathrm{a}$ significant negative relationship exists between the ratio of tourism receipts to GNP and population size. In the present paper, we adopt this simple definition of country size. 
While these preliminary remarks may not sound too promising for countries specialising in tourism, the endogenous growth setting is nevertheless the one we need to consider in order addressing fact (i). In particular, Lucas's (1988) two sector endogenous growth model is simple and detailed enough for our purpose of finding the conditions under which tourism specialisation is not a growth-damaging option. These conditions are discussed at length in Lanza and Pigliaru (1994) and (1995). Here we briefly summarise the main thrust of the argument, so to ease the forthcoming discussion about fact (ii), in which we use the same formal framework.

Consider a two-sector world in which the engine of growth -- the accumulation of human capital -- takes the exclusive form of learning-bydoing, so that pure competition prevails. The technology to produce sectoral outputs $y_{i}$ is as follows:

$$
y_{i}=h_{i} L_{i} \quad(i=1,2)
$$

where $h_{i}$ is human capital, which determines labour productivity in the sector, and $L_{i}$ is the labour force allocated to the sector. For the time being we assume that all existing countries have the same size of the overall labour force $(\mathrm{L}=1)$. This assumption will be dropped in the next section. In each sector the potential for learning-by-doing is defined by a constant, $\lambda_{i}$. In our case, manufacturing $(\mathrm{M})$ is the "high technology" sector, so that $\lambda_{M}>\lambda_{\mathrm{T}}$, where $\mathrm{T}$ stands for tourism ${ }^{5}$. In each period, with knowledge accumulation driven by leaming-by-doing with external economies linking all firms within the same sector, and no intersectoral spillovers ${ }^{6}$, the increase in his simply proportional to the sector's output [see eq. (1)], so that:

5 This assumption may be justified in terms of the importance of services in tourism and of the fact that, over a long period, productivity growth in services has lagged behind that in manufacturing. For instance, among the OECD economies as a whole, output per person employed grew between 1960 and 1993 by an average of $1.6 \%$ per annumin services but by $3.7 \%$ in manufacturing [Temple (1997)].

6 The joint presence of intersectoral of knowledge generates substantial changes in the results of Lucas's model. In particular, their presence, when combined with that of international spillovers, tends to rule uneven growth out. See Murat and Pigliaru (1998). 
(2) $\frac{\dot{h_{i}}}{h_{i}}=\lambda_{i} L_{i}$.

International trade will force all countries to specialise completely according to the comparative advantage they have when trade opens up (on this, more below, in section 3). The growth rate of a country therefore depends on such complete specialisation, according to:

$$
\frac{\dot{y}_{i}}{y_{i}}=\lambda_{i} .
$$

Therefore, productivity grows faster in countries specialised in $\mathrm{M}$ (measured in terms of this good) than in the other countries (measured in terms of T). However, with preferences assumed to be homothetic and identical everywhere, the terms of trade move in favour of the slow-growing good, tourism, at a constant rate. With CES preferences

the rate of change of $p \equiv p_{T} / p_{M}$ is equal to $\left(\dot{y}_{M} / y_{M}-\dot{y}_{T} / y_{T}\right) \sigma^{-1}$, where $\sigma$ is the elasticity of substitution. With complete specialisation, therefore:

$$
\frac{\dot{p}}{p}=\frac{\lambda_{M}-\lambda_{T}}{\sigma} .
$$

Comparing now the growth rates associated with the two available patterns of specialisation in terms of a common good (M, for instance), we find that tourism is the growth-maximising specialisation if

$$
\frac{\lambda_{\mathrm{M}}-\lambda_{\mathrm{T}}}{\sigma}>\left(\lambda_{\mathrm{M}}-\lambda_{\mathrm{T}}\right) \text {, }
$$

that is, if $\sigma<1$. In words, tourism is not harmful for growth if the international terms of trade move in its fast enough to more than offset the difference in sectoral productivity growth. For this to happen, the two goods must not be close substitute.

The empirical value on the elasticity of substitution between manufactured goods and the tourism is therefore an important piece of the evidence when it comes to evaluating the long-run consequences for an economy that specialised in tourism. Using a OECD countries data set, Lanza (1997) finds that in most cases $\sigma$ is indeed lower than one.

So far, we have defined an explanatory hypothesis about point (i) above. The aim is now to extend the underlying model in order to obtain an 
explanation of the second empirical regularity - that is, tourism countries are generally small - consistent with the explanation put forward for the first one.

\section{Country size, tourism and growth}

Before turning to our own hypothesis about point (ii), we discuss a simple and appealing hypothesis suggested by Cellini and Candela (1997). In their paper, the two authors adopt the Lucas based explanation of point (i) as first suggested in Lanza and Pigliaru (1994), and try to extend it to address point (ii). O ur aim here is to show that, however appealing, their hypothesis is inconsistent with their more general aim - that is, to obtain a joint explanation of the two regularities within the same theoretical framework.

\subsection{Explanation one Doss a cantrys sabsolutesizematter?}

Recently, Candela and Cellini (1997) (CC hereafter) have provided an explanation based on the idea that countries with different absolute (population) sizes face different opportunity costs associated with tourism specialisation.7 More precisely, they note that, within Lucas's framework, "the smaller is a small-economy, the easier the pattern of the term of trade offsets the technology gap disadvantage", so that "the opportunity cost of specialisation in tourism is smaller, the smaller is the country" [CC (1997), p. 457] ${ }^{8}$. This point can be shown easily by assuming an exogenous constant positive growth rate of the terms of trade $p \equiv p_{T} / p_{M}$. Let us consider small countries of two different sizes, $i$ and $j$, and assume that $L_{j}>L_{i}$. As CC point out, the growth maximising choice of each country facing an exogenous $\dot{p} / p$ depends on its size. For instance, if $\dot{p} / p>\left(\lambda_{M}-\lambda_{T}\right) L_{j}$, countries of the $\mathrm{j}$ type find it optimal to specialise in tourism. If so, countries of the i type would also be specialised in tourism. For them, tourism is clearly an even more convenient option than for $j$ countries.

Implicitly, this example supports CC major point: when countries are of heterogeneous absolute size, if onlyonegaup of themiswillingtospeialisein tarism this gaup mist the onefomed by the cuntries of thesmallest size Indeed, a

${ }^{7}$ More detailed results are presented in Lanza A. and F. Pigliaru (1998).

8 On the relation between absolute size of the natural resource endowments and economic growth, see also Sachs and Warner (1995), and Gylfason, Herbersson and Zoega (1997). 
value of $\dot{p} / p$ exists such that:

$$
\left(\lambda_{M}-\lambda_{T}\right) L_{i}<\dot{p} / p<\left(\lambda_{M}-\lambda_{T}\right) L_{j} .
$$

Here $\mathrm{i}$ countries are optimally specialised in tourism, and $\mathrm{j}$ countries in manufacturing. However, a crucial joint prediction is also revealed by this example - a rather troublesome one. Larger countries grow faster than smaller ones; therefore, countries specialised in manufacturing grow faster than tourism countries.

As point (i) above suggests, the available evidence does not support these predictions. Countries specialised in tourism are small and they grow fast -- faster than the others, on average. Countries specialised in tourism have experienced a per capita income growth of about $5 \%$ per year during the period 1985-1994. During the same period the average growth rate at the World level was equal to $0.8 \%$, and for the subset of developing countries it was equal to $3.6 \%$ [mainly due to China's high performance during the period: $8.3 \%$ ].

In other words, extending Lucas's approach by introducing heterogeneity in absolute size across countries does generate an explanatory hypothesis of point (ii). However, the same modification makes the model incapable of jointly explain point (i). Analytically, it is not difficult to single out the source of the problem. To address point (ii), CC rely on a strong and generally regarded counterfactual scale effect based on the size of the labour force. As a consequence, the smaller countries' growth path is the slower one ${ }^{9}$.

In the following, we propose an alternative explanation in which a resource-based comparative advantage is what characterises the heterogeneity across the existing countries. In our proposed explanation, we abstract again (as in section 2) from differences in absolute size in order to get rid of the scale effect discussed above.

\subsection{Explanationtwa Dordativeresarceendbunents matter?}

Most of the small fast growing countries specialised in tourism

9 This scale effect is typical of the class of model to which Lucas's belongs. All the learning-by-doing models of this type are characterised by a scale effect attached to the endowment of the fixed factor of production (labour, in our simple case). In general, normalisation is adopted in these models precisely to get rid of such effect, which many economists would regard as a rather "counterfactual" one [see Barro and Sala-i-Martin (1995)]. 
ground their supply of tourism services on their natural resources. This suggests a second hypothesis - alternative to the one based on absolute size - to address point (ii). Some indirect evidence available in the empirical literature, as well as casual inspection of the data, suggest that small countries are likely to be characterised by higher than average per-capita amounts of the natural resource which attracts tourists ${ }^{10}$.

In this section we show how, in our dynamic setting, comparative advantage in tourism depends on the size of the natural resource suitable for tourism development reativeto some measure of the country's size, such as its overall population. In a rather traditional fashion, heterogeneity in relative endowments of natural resources explains the pattern of specialisation obtained in the international marketplace. Clearly, this analysis can be regarded as an explanation of point (ii) only insofar as the relative endowment of natural resources is shown to be significantly higher in small tourism countries than in the non-tourism countries, especially the larger ones. Our suggestion is that maybe absolute size is just a proxy for the true, economically meaningful variable associated with natural resource endowments. Detailed empirical work is clearly needed to validate this suggestion.

The discussion in section 3.1 makes clear that the heterogeneity in relative endowments should be formalised while controlling for the growth effect associated to the size of the labour force. Therefore, our first assumption is $L_{i}=1 \forall i$. Second, we assume that a limit exists to the capacity of the tourism sector to absorb the labour force. More precisely, we assume that (a) the resource suitable for tourism development is an exogenous natural endowment, $\bar{R}$; (b) this resource is combined in fixed proportion, at zero costs, with labour to produce tourism services. Let $\rho$ define the fixed quantity of $\bar{R}$ per unit of labour required by the tourism technology. Then the sector's production function is:

$$
y_{T}=\rho h_{T} L_{T}
$$

Given this technology, the maximum amount of labour an economy can allocate to the tourism sector $\left(\bar{L}_{T}\right)$ is constrained by the natural endowment according to:

${ }^{10}$ For instance, Liu and Jenkins find a strong negative correlation between the log of tourist arrivals per square meter an the log of country size [Liu and Jenkins (1996), p. 112]. 


$$
\bar{L}_{T}=\bar{R} / \rho
$$

For simplicity, let us choose units so that $\rho=1$ and therefore $\bar{L}_{T}=\bar{R}$. With endowments not uniform across countries, a useful heterogeneity may emerge. Countries with a relative large endowment of $\bar{R}(\bar{R} \geq 1)$ have the option to allocate their whole labour force in tourism; this option is not available for countries with smaller endowments $(\bar{R}<1)$.

Given that in our framework all countries are "small", this is the closer we can get to the idea that in reality small countries are more likely than greater ones to have a large endowment of the appropriate natural resource relative to the size of the labour force. With this kind of heterogeneity, the dynamics of the system under an autarchic regime gives rise to a resource-based comparative advantage that, together with the result discussed in section 2, offers a unified explanation of the two above-quoted points (i) and (ii). To see this, we first recall the determination of the autarchic steady state for a non-constrained representative country. Later we will introduce the constraint and will evaluate the consequences on the determination of comparative advantage.

Define $q$ as the price of tourism relative to the price of the manufacturing good in autarchy. Pure competition implies that the rate of change of qis equal to:

$$
\frac{\dot{q}}{q}=\frac{\dot{h}_{M}}{h_{M}}-\frac{\dot{h}_{T}}{h_{T}}=\lambda_{M}-\left(\lambda_{M}+\lambda_{T}\right) L_{T}
$$

The level of $L_{T}$ in each period is obtained solving the model for the static momentary equilibrium. In this equilibrium we have11:

$$
L_{T}=\left[\left(\alpha_{T} / \alpha_{M}\right)^{-\sigma} q^{\sigma-1}+1\right]^{-1} .
$$

For $\sigma<1$ the first derivative of (9) with respect to $q$ is positive, and the second is negative. Using (9) in (8) therefore we see that in this case a stable steady-state value of $\mathrm{q}$ exists [such a steady state is unstable if $\sigma>1$, as in Lucas (1988)]. For our purposes, it is worth studying this equilibrium in greater detail. Eq. (8) indicates that the value of $L_{T}$ corresponding to the

11 See Lucas (1988). 
stationary value $q^{*}$ is:

$$
L_{T}^{*}=\frac{\lambda_{M}}{\lambda_{M}+\lambda_{T}} .
$$

We plot the right hand sides of (9) and (10) in Fig. 1. Notice that for any given value of $q^{\prime}$, the difference between $L_{T}^{*}$ and $L_{T}\left(q^{\prime}\right)$ yields a measure of the rate of change of $q$ More precisely,

$$
L_{T}^{*}-L_{T}=\frac{\dot{q}}{q\left(\lambda_{M}+\lambda_{T}\right)} .
$$

As for comparative advantage, if all economies are similar, they will all end up with $q^{*}$, and no long run pattem of comparative advantage emerges. This is not so if countries are characterised by a sufficient degree of heterogeneity. Assume that resource endowments are such that the constraint $\bar{L}_{T}<1$ characterises a subset of countries. Two possibilities now arise. The first is that:

$$
\frac{\lambda_{M}}{\lambda_{M}+\lambda_{T}}<\bar{L}_{T}<1
$$

In this case the constraint has no consequences on the determination of comparative advantage. If, instead,

$$
\bar{L}_{T}<\frac{\lambda_{M}}{\lambda_{M}+\lambda_{T}}<1
$$

then in these economies a stationary value of qdoes not exist, since qgrows at a positive constant rate equal to $\lambda_{M}-\left(\lambda_{M}+\lambda_{T}\right) \bar{L}_{T}$ (see Fig. 2).

In the long run the countries in this subset produce both the manufacturing and the tourism goods, with a stable (constrained) allocation of labour. However, such a stable allocation implies an ever-increasing relative price of tourism. The consequence for comparative advantage is straightforward. In the long run, countries in which the resource constraint is not binding end up obtaining the stationary price $q^{*}$. Countries where the constraint binds end up with a higher (and increasing) relative price of tourism. Notice that this pattern of comparative advantage is independent of 
the countries' initial conditions, and that this is so because $\sigma<1^{12}$.

When we add up this finding to the outcome described in section 1 , we find that, as long as the elasticity of substitution in consumers' preferences is low enough: (a) countries with endowments of suitable natural resources large relative to the size of their labour force are likely to develop a comparative advantage in tourism; (b) these countries grow faster than those who specialise in the manufacturing sector.

\section{Discussion and conclusions}

Cross-section data on economic growth and tourism specialisation for the decade 1985-95 show that a number of tourism countries grow fast and are small. In this paper we have proposed a joint explanation based on a simple two-sector endogenous growth model. While the model highlights an important reason why tourism specialisation is not harmful for growth, the explanation put forward for the issue concerning size is perhaps more tentative. In this respect, our analysis suggests that what matters for explaining specialisation in tourism is a country's relative endowment of the natural resource, rather than its absolute size. Our suggestion is that maybe absolute size is just a proxy for an economically more meaningful variable. To validate this suggestion, future research should produce detailed evidence on the existence of a negative relation between absolute size and per-capita amounts of natural resources.

More generally, we need more empirical work to assess the robustness of the two rather scanty empirical observations presented in this paper. Among others, two questions are worth underlining. The first concerns the size issue. How robust is the relation between size, tourism specialisation and growth?

Second, the whole analysis developed in this paper assumes that the observed growth rates are a reliable representation of the long-run rates - the only ones we have analysed theoretically. Problems with this assumption are particularly acute in the case of growth based on natural resources. A nonoptimal use of the natural resources might initially spur high growth rates that turn out to be unsustainable in the longer nun, in a way similar to the one described by the literature on the so-called "Dutch disease". In our

12 With $\sigma>1$, all constrained countries would obtain a comparative advantage in manufacturing, but the comparative advantage of the unconstrained countries would crucially depend on their initial conditions. 
model, supplying the tourism service does not reduce the stock of the resource available in the economy. However, were such a reduction take place, an important consequence would soon emerge: the process might easily induce the country's loss of comparative advantage in tourism, with negative consequences for its long-nun growth rate. As a consequence, one key empirical question that remains to be answered is how sustainable the currently observed high growth rates of a number of tourism countries are in the long nun. 
14

\section{References}

Aghion P. and P. Howitt (1998), Endogenas Growth Thery, Cambridge, MA: The MIT Press.

Barro R. and X. Sala-i-Martin (1995), EconomicGronth New York: McGrowHill.

Candela G . and Cellini R. (1997), Countries' size, consumers' preferences and specialization in tounism: a note, Rivista Intemezionaled SäzeEconmide eCommaciali, 44, 451-57.

Grossman G. and Helpman E. (1991), Imovation and gouth in the gdbal ecomony, Cambridge, MA: The MIT Press.

Gylfason T., Herbertsson T.T. and Zoega G. (1997), A mixed blessing: natural resources and economic growth Cetrefor EconmicPdioyReserth D.P. no. 1668

Lanza A. (1997), Is tourism harmful to economic growth, Statistica, n.3.

Lanza A. and Pigliaru F. (1994), The tourism sector in the open economy, RiuistaIntemezionaled SäezeEconmideeCommaciali, 41.

Lanza A. and Pigliaru F. (1995), Specialisation in tourism: the case of a small open economy, in P. Nijkamp and P. Coccossis (eds), Sustainabletanism dadqpmet, Aldershot: Avebury.

Liu Z. and Jenkins C.L. (1996), Country size and tourism development: a cross-nation analysis, in: L. Briguglio et al. (eds), Sustainalde toursmin islandsandsmall states issuesandpdices London: Pinter, 90-117.

Lucas R. (1988), On the mechanics of economic development, Jamal of Mondary Economics 22, 3-42.

Murat M. and Pigliaru F. (1998), International trade and uneven growth: a model with intersectoral spillovers of knowledge, Jamal of Intemational TradeandEconomicDediqmet, 7, 221-36.

Sachs J. and Warner A. (1995), Natural Growth Abundance, Harvard Insitute for Intemational Dedepment, Dedqumet DisassionPapern. 517a.

Sinclair M.T. (1998), Tourism and economic development: a survey, Jamal of Dexdqpat Suries 34, 1-51.

Temple P. (1997), The Performance of U.K. Manufacturing, Centre for EconomicForeating LondonBusinss Sthod DisassionPaper 14/97 
Figure 1

$L_{T}^{*}<\bar{L}_{T}$

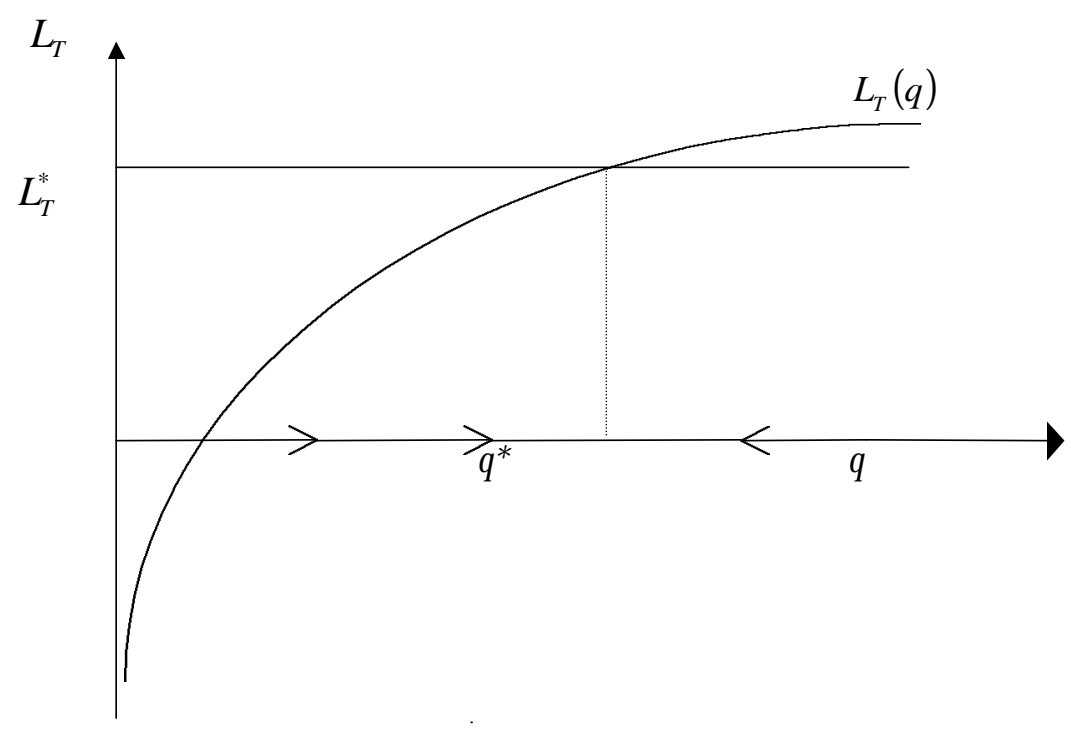

Figure 2

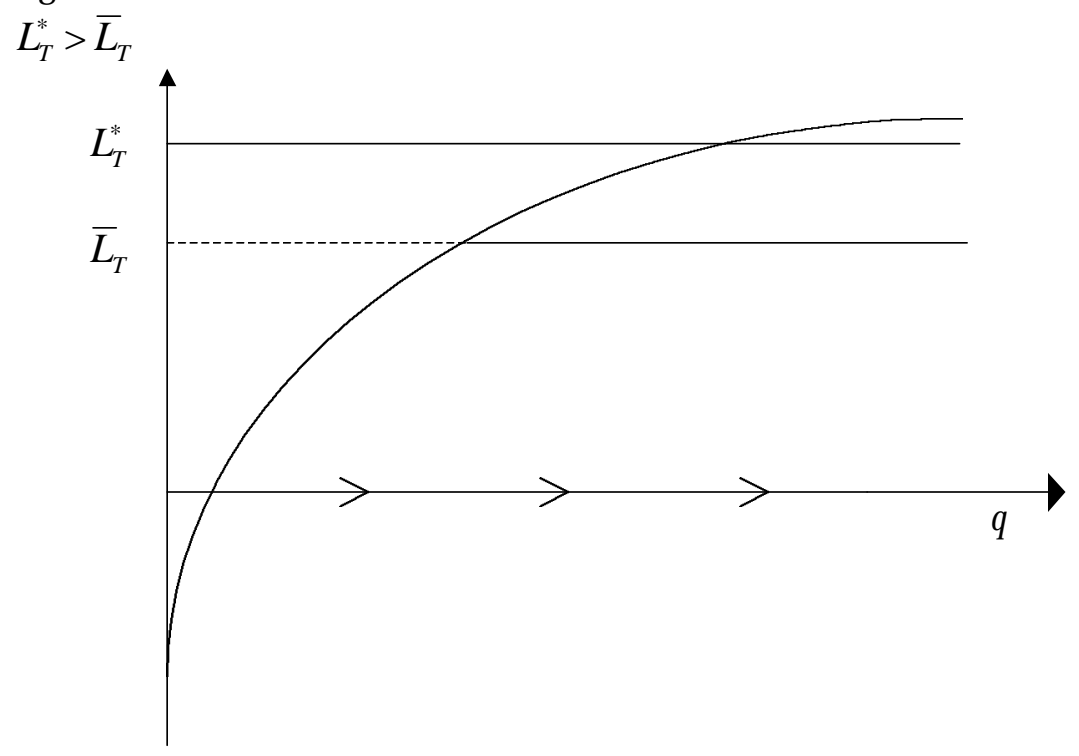




\section{Contributi di Ricerca CRENoS}

\section{Gli abstrad sano disponibili in: http:/ / www.crenos.unica.it}

95/ 1 Antonio Sassu, Raffaele Paci, Stefano Usai, "Patenting and the Italian Technological System"

95/ 2 Rinaldo Brau, "Analisi econometrica della domanda turistica in Europa: implicazioni per lo sviluppo economico delle aree turistiche"

95/ 3 Sergio Lodde, "Allocation of Talent and Growth in the Italian Regions"

95/ 4 Stefano Usai, Marco Vannini, "Financial Development and Economic Growth: Evidence from a panel of Italian Regions"

95/ 5 Raffaele Paci, Stefano Usai, "Innovative Effort, Technological Regimes and Market Structure"

96/ 1 Rinaldo Brau, Elisabetta Strazzera, "Studio di valutazione monetaria per il parco nazionale del $\mathrm{G}$ ennargentu. Indagine preliminare"

96/ 2 Emanuela Marrocu, "A Cointegration Analysis of W.A. Lewis' Trade Engine Theory"

96/ 3 Anna Maria Pinna, "Sectoral Composition of Trade and Economic Growth: some New Robust Evidence"

96/ 4 Riccardo Marselli, Marco Vannini, "La criminalità nelle regioni italiane: il ruolo del sistema sanzionatorio, delle motivazioni economiche e del contesto sociale"

96/ 5 Raffaele Paci, Riccardo Rovelli, "Do Trade and Technology reduce Asymmetries? Evidence from Manufacturing Industries in the EU"

96/ 6 Paolo Piacentini, Paolo Pini, "Domanda, produttività e dinamica occupazionale: un'analisi per "moltiplicatori"”

96/ 7 Raffaele Paci, Francesco Pigliaru, " $\beta$-Convergence and/ or Structural Change? Evidence from the Italian Regions"

96/ 8 D aniela Sonedda, "Commercio internazionale e crescita economica nei casi della Corea del Sud e delle isole Filippine: un'analisi di causalità"

96/ 9 Raffaele Paci, "More Similar and Less Equal. Economic Growth in the European Regions"

96/ 10 Elisabetta Schirru, "Modelli di determinazione del tasso di cambio: un'analisi di cointegrazione"

96/ 11 Riccardo Contu, "Rapporti scientifico-contrattuali e adattamenti istituzionali nella dinamica impresa-accademia: persistenza delle New Biotechnology Firms nell'industria biotecnologica USA degli anni '90"

96/ 12 Francesco Pigliaru, "Economia del turismo: note su crescita, qualità ambientale e sostenibilità" 
97/ 1 Raffaele Paci, Andrea Saba, "The empirics of Regional Economic Growth in Italy. 1951-1993"

$97 / 2$ Michael Pontrelli, "Un'analisi econometrica del contenuto informativo della struttura a termine dei tassi di interesse tedeschi"

97/ 3 Raffaele Paci, Francesco Pigliaru, "European Regional Growth: Do Sectors Matter?"

97/ 4 Gianna Boero, Costanza Torricelli, "The Expectations Hypothesis of the Term Structure: Evidence for Germany"

97/ 5 Raffaele Paci, Francesco Pigliaru, "Is Dualism Still a Source of Convergence Across European Regions?"

97/ 6 Sergio Lodde, "Human Capital and Growth in the European Regions. D oes Allocation Matter?"

97/ 7 Marta Sanna, "Spillover tecnologici nord-sud: una nota a Coe Helpman - Hoffmaister"

97/ 8 RaffaelePaci, Stefano Usai, "Technological Enclaves and Industrial Districts. An Analysis of the Regional Distribution of Innovative Activity in Europe"

98/ 1 Pinuccia Calia, Elisabetta Strazzera, "Bias and Efficiency of Single Vs. Double Bound Models for Contingent Valuation Studies: A Monte Carlo Analysis"

98/ 2 Rossella Diana, Elisabetta Serra, Elisabetta Strazzera, "Politiche non sostenibili per lo sviluppo sostenibile. Il caso del Parco del Gennargentu"

98/ 3 Raffaele Paci, Francesco Pigliaru, "G rowth and Sectoral Dynamics in the Italian Regions"

98/ 4 Adriana Di Liberto, James Symons, "Human Capital Stocks and the D evelopment of Italian Regions: a Panel Approach"

98/ 5 Sergio Lodde, "Invidia e imprenditorialità Alcune note sul ruolo delle emozioni nello sviluppo economico"

98/ 6 Roberto Marchionatti, Stefano Usai, "International Technological Spillovers and Economic G rowth. The Italian Case"

98/ 7 Elisabetta Strazzera, "Option Values and Flexibility Preference"

99/ 1 Marzio Galeotti, Alessandro Lanza, "Desperately Seeking (Environmental) Kuznets"

99/ 2 Francesco Pigliaru, "D etecting Technological Catch-Up in Economic Convergence"

99/ 3 Rosanna Carcangiu, Giovanni Sistu, Stefano Usai, "Struttura socioeconomica dei comuni della Sardegna. Suggerimenti da un'analisi cluster"

99/ 4 Adriana Di Liberto, James Symons, "Some Econometric Issues in Convergence Regressions"

99/ 5 Pinuccia Calia, Elisabetta Strazzera, "A Sample Selection Model for Protest Non-Response Votes in Contingent Valuation Analyses" 
